\title{
Exceção, história e barbárie no Brasil: três tempos, três cenas
}

\section{Exception, history and barbarism in Brazil: three times, three scenes}

\author{
Gustavo Silveira Ribeiro \\ Universidade Federal de Minas Gerais, Belo Horizonte, Brasil \\ gutosr1@yahoo.com.br
}

Resumo: O artigo procura compreender, na esteira de Walter Benjamin e Giorgio Agamben, como a história social e cultural brasileira pode ser lida a partir dos topoi da exceção e da barbárie, vistos a partir da obra de três autores e três obras (de valor literário bastante desigual) da literatura brasileira moderna e contemporânea.

Palavras-chave: barbárie; exceção; história do Brasil; Graciliano Ramos; Bernardo Kucinski.

\begin{abstract}
This article seeks to understand social history and Brazilian culture using the topoi exception and barbarism, taken from the works of Giorgio Agamben and Walter Benjamin. We will approach those themes using tree authors and tree works (of unequal literary value) from modern and contemporary Brazilian literature.
\end{abstract}

Keywords: barbarism; exception; brazilian history; Graciliano Ramos; Bernardo Kucinski.

1

A imagem terrível de um mundo invertido, estruturado a partir da violência punitiva e do cancelamento sistemático de direitos e garantias individuais, talvez seja a mais adequada para descrever, numa visão de conjunto, a história brasileira do século XX. Desde a barbárie da Campanha de Canudos, espécie de sangrenta introdução ao que viria a se tornar regra no país - a criminalização, o encarceramento e o extermínio de pobres, opositores e indesejáveis - até o Massacre do Carandiru, na última década do século, a confirmação final (mas não a última) da tânato-política (cf. PENNA, 2013, p. 74) que pautou, e ainda pauta, a vida nacional, o que se pode observar é a continuidade, poucas vezes interrompida, da vigência 
entre nós daquilo que, brilhantemente, o filósofo italiano Giorgio Agamben chamou estado de exceção (cf. AGAMBEN, 2004). Leitor de Carl Schmitt e Walter Benjamin, que também já haviam esquadrinhado a questão por outros caminhos, Agamben vem estudando, ao longo das últimas décadas, a relação entre poder soberano e biopolítica, entre o controle das formas de vida e administração geral da morte. O centro de suas preocupações repousa na presença (e no significado político) daqueles indivíduos que ele vai definir como homo sacer, isto é, o homem sacro, aqueles cuja morte não é passível de punição, e cuja vida, por extensão, é tão somente um fato biológico, vida nua, paradoxalmente despida de qualquer sacralidade - vida simplesmente matável (cf. AGAMBEN, 2010). Um dos desdobramentos mais importantes desse projeto de fôlego, que até agora já se expande em quase dez livros, e que pretende observar os muitos desdobramentos da máquina social que suporta e sobredetermina o homo sacer, tem a ver justamente com o problema da excepcionalidade jurídica que habita o coração das democracias constitucionais do Ocidente, das quais o Brasil, bem ou mal, faz parte desde a Proclamação da República em 1889. Segundo Agamben - que aqui segue também as pistas deixadas por Derrida em Força de lei, segundo o qual a autoridade jurídica se sustenta em torno a uma "violência performativa" (DERRIDA, 2007, p. 24), originária e fundadora, e um "fundamento místico" (DERRIDA, 2007, p. 21), um ato de fé que o justifica, ao fim e ao cabo - há um conjunto de dispositivos jurídicos nas leis que regem os Estados democráticos que permitem, paradoxalmente, a suspensão de qualquer lei, a interrupção do funcionamento institucional e a concentração do poder nas mãos do soberano, aquele que, em última instância, tem o direito de decidir sobre a vida e a morte, sobre os momentos nos quais uma dada situação emergencial pode (ou deve) se transformar em estado de exceção. Nas 
palavras do próprio Agamben, que aprofunda a questão aproximando-a da experiência histórica dos Estados totalitários:

\begin{abstract}
O totalitarismo moderno pode ser definido, nesse sentido, como a instauração, por meio do estado de exceção, de uma guerra civil legal que permite a eliminação física não só dos adversários políticos, mas também de categorias inteiras de cidadãos que, por qualquer razão, pareçam não integráveis ao sistema político. (AGAMBEN, 2004, p. 13)
\end{abstract}

Pensado idealmente como ferramenta extrema para a garantia do estado de direito, a possibilidade do estado de exceção tornou-se, sempre conforme Agamben, o "paradigma de governo dominante na política contemporânea" (AGAMBEN, 2004, p. 13), impondo uma reversão que estrutura, aporeticamente, os Estados democráticos. Aquilo que neles, por definição, deveria constituir-se como exceção, desvio, anormalidade, passa a ser a norma, a regra aceitável, a técnica de governo preferencial: “O estado de exceção não é um direito especial (como o direito de guerra), mas enquanto suspensão da própria ordem jurídica, define seu patamar ou seu conceito-limite.” (AGAMBEN, 2004, p. 15) A suspensão de garantias individuais, do ordenamento social baseado na presunção de inocência, na inviolabilidade do lar (e do segredo) e na liberdade de movimentos; a militarização, enfim, da vida e das relações entre o Estado e os cidadãos - em nome de uma ameaça qualquer a essa mesma ordem e aos mesmos cidadãos - são algumas das marcas mais nocivas do problema que aqui se coloca, e que tem no Brasil, como dissemos, uma vigência e uma visibilidade insuportáveis.

A sucessão contínua no país de períodos ditatoriais (alguns deles de aparência e estrutura legal), a repetição de chacinas, a manutenção de dispositivos jurídicos excepcionais (como, por exemplo, nunca é demais lembrar, os chamados "autos de resistência" da polícia militar, e a infame Lei de Segurança Nacional), a ocupação militar de partes do território como estratégia de controle social, tudo isso permite descrever o Brasil dos últimos cem anos como estado de exceção permanente, num quadro dramático no qual foram mudando apenas 
os elementos de um processo dicotômico excludente e violento, armado sempre a partir da mistificação da comunidade nacional.

Logo no início do século, com a jovem República e sua conformação oligárquica e antipopular, o inimigo era identificado aos "bestializados" (cf. CARVALHO, 1998; HARDMAN, 1998), os sertanejos, ex-escravos, trabalhadores braçais marginalizados cuja revolta era tomada como ameaça irracionalista, assumindo os contornos do fanatismo religioso de viés messiânico e contrarrevolucionário (como nos casos de Canudos e do Contestado) ou do perigo sanitário (como na Revolta da Vacina e nas remoções de miseráveis executadas pelas reformas do prefeito Pereira Passos, do Rio de Janeiro, então capital do país); a sua dominação e eventual extermínio era urgente, demandando a aplicação de políticas discricionárias ou francamente assassinas. Umas e outras redundaram ou na guerra civil de caráter genocidário ou no incremento da segregação social das periferias e favelas; ambas experiências históricas marcadas pelo fenômeno comum da criminalização da pobreza e da politização absoluta dos corpos, da cultura e das formas de vida.

Num momento posterior, com o crescimento das cidades e a formação de um proletariado relativamente numeroso, o adversário passará a ser identificado ao comunismo, espécie de ideologia alienígena (segundo os discursos oficiais) que infiltrava, no corpo da nação que se queria una e indivisível, imune aos choques de classe, o elemento desagregador estrangeiro, a ameaça externa que no entanto vivia e atuava dentro do país. A implementação do Estado Novo, em 1937, e o Golpe Civil-Militar de 1964, constituem, sem dúvida, e em que pesem as suas inúmeras diferenças, os momentos em que a suspensão do Estado democrático de Direito foi justificada pela necessidade da preservação da comunidade e da soberania da nação, ganhando a forma comum do combate violento, estatal e civil, ao agente vermelho. 
Naquele que talvez seja o ápice do problema que aqui levantamos, chegou-se mesmo a formular a tese, a um só tempo jurídica e política, da Doutrina de Segurança Nacional, plataforma de lançamento e cobertura ideológica para a perseguição, a tortura, o exílio e o extermínio de opositores que se desencadeou a partir, principalmente, da promulgação do AI5 em 1968, Ato Institucional que consolidou a ditadura e mergulhou o país num dos seus períodos mais duros e obscuros.

No âmbito do presente, a vida nas favelas e periferias de qualquer dos grandes centros urbanos brasileiros confirma, dia após dia, a persistência da norma anormal, do absurdo e da brutalidade tornadas matéria comum, existência cotidiana. O poder territorial do crime organizado, o abandono quase completo do Estado, a violência policial ostensiva, desdobrada em interrogatórios, tortura e assassinatos muito frequentes, tudo isso aponta para a continuidade da exceção, para além dos períodos de conturbação política aberta, exceção mesmo, e talvez principalmente, nos tempos de paz, nos quais a aparente normalidade encobre o sentido do controle e da violência a que os oprimidos estão renovadamente submetidos. Tal realidade parece confirmar aquilo que, dramaticamente, afirmava Walter Benjamin ainda nos anos 1930, ao mostrar que os miseráveis já conheciam aquilo que todos começavam a experimentar na Europa das guerras mundiais e do totalitarismo: "A tradição dos oprimidos nos ensina que o estado de exceção em que vivemos é na verdade a regra geral” (BENJAMIN, 2004, p. 226).

eISSN: $2179-8478$ 
Se nem sempre o pensamento social brasileiro compreendeu dessa maneira o percurso histórico nacional no século XX, descrevendo-o, muitas vezes, a partir da conciliação de classes e dos arranjos políticos que sem dúvida pautaram também o quadro social do país, preferindo construir narrativas que privilegiassem a normalização e a linearidade de uma trajetória unitária e institucional da nação, a literatura, por sua vez - como espaço diferido do registro histórico e da reelaboração do tecido afetivo que envolve e dá forma ao corpo social , pôde tornar visível, em diferentes contextos, as fraturas da comunidade nacional, seus interditos profundos e as violências que a constituem. Se tratamos de pensar até aqui o país tendo como pano de fundo a questão da anomalia jurídica e política do estado de exceção, propomos a partir de agora observar em três narrativas diferentes (na verdade excertos de narrativas) como se articula, diante do problema da exceção, a dupla experiência possibilitada pela literatura: ao mesmo tempo ela o transforma em imagem, isto é, em representação problemática historicamente informada, ela também faz dele matéria do pensamento, objeto de reflexão conceitual. Os textos a que nos referimos são os seguintes: o relato autobiográfico Memórias do cárcere (1953), de Graciliano Ramos; a trilogia Os subterrâneos da liberdade (1954), de Jorge Amado, e o romance K. - Relato de uma busca (2011), de Bernardo Kucinski. Apesar das inúmeras diferenças (formais e ideológicas) que os separam, esses três livros perfazem uma mesma série literária marcada pela violência, pela censura e pela relação que mantém (de caráter testemunhal, diríamos) com períodos dominados pelos regimes ditatoriais que se instalaram no Brasil, sucessivamente nas décadas de 1930 e 1960. Em cada um deles será destacada uma cena, lida aqui como uma mônada em que se concentram os procedimentos narrativos fundamentais e os sentidos mobilizados pelos textos. Nem é preciso 
dizer que se tratam, indubitavelmente, de três cenas excepcionais, ou seja, escritas sob o signo da exceção.

Publicado postumamente em quatro volumes no fim do ano de 1953, as Memórias do cárcere narram a passagem de seu autor, Graciliano Ramos, por quatro cadeias diferentes no período em que esteve em poder da polícia política de Governo Vargas, entre março de 1936 e janeiro de 1937. Detido sem acusação formal em sua casa, em Maceió, o escritor, já àquela altura um homem público, com dois romances impressos e serviços relevantes prestados à administração pública (como prefeito de Palmeira dos Índios-AL e Diretor da Instrução Pública do Estado de Alagoas), é apanhado na vaga repressiva que se seguiu à derrota do Levante Comunista de novembro de 1935, implicitamente suspeito de manter relações com o Partido Comunista. Tendo vivido em diferentes instalações penais, ora cercado de presos políticos, ora misturado aos presos comuns, na sua maioria ladrões e assassinos pobres, Graciliano assistiu, desde o cárcere, ao endurecimento da administração oligárquica de Getúlio Vargas, até então um governo que respirava fumaças de democracia e flertava (simultaneamente) com o totalitarismo europeu, revelando, a partir daí, a sua tendência autoritária e fascista, que se confirmou pouco tempo depois com a implantação do Estado Novo, pela via do golpe, a partir do fim de 1937. O tratamento dispensado aos opositores do regime, isolados do restante do país e submetidos a privações, torturas e morte, dava bem a medida do que significava, concretamente, o "estado de guerra" (equivalente jurídico, no Brasil, ao estado de exceção) no qual estava imerso, por decreto, todo o país. Observemos o que registra o escritor sobre a sua chegada, acompanhado de muitos outros prisioneiros, à Colônia Correcional de Dois Rios, na Ilha Grande - verdadeiro campo de concentração instalado no país: 
Virei-me, enxerguei um tipinho de farda branca, de gorro branco, a passear em frente às linhas estateladas. Era vesgo e tinha um braço menor que o outro, suponho. Não me seria possível afirmar, foi impressão momentânea. Um sujeito miúdo, estrábico e manco a compensar todas as deficiências com uma arenga enérgica, em termos que me arrisco a reproduzir, sem receio de enganar-me. Um bichinho aleijado e branco, de farda branca e gorro certinho, redondo. Parecia ter uma banda morta. O discurso, incisivo e rápido, com certeza se dirigia aos recém-chegados:

- Aqui não há direito. Escutem. Nenhum direito. Quem foi grande esqueça-se disto. Aqui não há grandes. Tudo igual. Os que têm protetores ficam lá fora. Atenção. Vocês não vêm corrigir-se, estão ouvindo? Não vêm corrigir-se: vêm morrer.

Embora não me restasse ilusão, a franqueza nua abalou-me: sem papas na língua, suprimiam-nos de chofre qualquer direito e anunciavam friamente o desígnio de matar-nos. Singular. Constituíamos uma sociedade numerosa, e não tínhamos nenhum direito, nem ao menos o direito de viver. Esquisita afirmação. [...] (RAMOS, 2008, p. 429; grifos nossos)

A formulação não poderia ser mais clara e concisa: "Aqui não há direito". É um corte preciso, uma delimitação objetiva entre o antes e o depois, o fora e o dentro, a norma rasurada e a exceção tornada regra. O comandante do campo de prisioneiros explicita o que, difusamente, já se podia perceber naquele período, pelo menos entre os detidos, as vítimas imediatas. Na vigência do estado de guerra em curso, na suspensão de todas as leis tornada ela mesma a lei definitiva, o único propósito do poder que se abateu sobre a sociedade (aqui metonimicamente representada no corpos dos encarcerados) revela a sua natureza: a administração da morte, a escolha final entre os que devem morrer - em nome da preservação da comunidade, de sua segurança - e os que devem, subjugados, ter sua vida mantida e integrada a um projeto nacional sem restos ou fissuras, sem contestação ou diferença (cf. MIRANDA, 1992).

A estratégia declarada da eliminação: "Não vêm corrigir-se: vêm morrer", sobrepujando a punição corretiva, a reintegração do indivíduo depois do período de sua sentença, não pode ser confundida, claro está, com a aplicação da pena capital, nesse exato momento não prevista em lei, mas logo regulamentada na Carta Magna do Estado Novo, promulgada em 1937. Extrema, a pena de morte ainda assim exige um aparelho legal e 
pressupõe um Estado de direito, no qual a possibilidade da defesa esteja ampla e previamente assegurada. O que se verificou no encarceramento e morte dos opositores do Governo Vargas, da qual o texto de Graciliano Ramos constitui importante testemunho, não passava por aí. A detenção arbitrária, sem processo, e o controle total dos corpos dos prisioneiros, submetidos à vontade dos carcereiros e dos governantes, indicava antes a suspensão de qualquer legalidade prévia e a instituição da excepcionalidade como padrão: a morte pelas mãos do Estado tornava-se ação ambígua, nem legal, por não estar codificada e regulamentada, nem de todo ilegal, uma vez que praticada sob a proteção difusa de uma legislação que suspendia toda as garantias anteriores. Essa situação intervalar, de fato incompreensível e absurda para os que nela se viam tramados, dá o tom fundamental das Memórias do cárcere e do que nela vai se formular como crítica ao "nosso pequenino fascismo tupinambá" (RAMOS, 2008, p. 12). Ao longo de todo o texto, Graciliano vai expor a singularidade da violência estatal a que estavam submetidos ele e os demais presos (como o trecho revela claramente) ao mesmo tempo em que percebe a inconcebível normalidade, a "franqueza nua" com que ela - e seu aparato institucional - se expunha.

Escritos e publicados em época muito próxima à do livro de Graciliano Ramos, 1954, os três romances de Jorge Amado que compõem o painel de Os subterrâneos da liberdadeOs ásperos tempos, A agonia da noite e A luz no túnel - enfocam um período pouco posterior da vida política brasileira, a ditadura do Estado Novo (1937-1945). Concebida como um autogolpe, a manobra política que possibilitou a ditadura visava concentrar ainda mais o poder nas mãos do chefe do executivo, Getúlio Vargas, com a intenção declarada de pacificar o país, debelando o perigo comunista, e moderniza-lo, ainda que a partir do alinhamento com potências estrangeiras beligerantes: primeiro a Alemanha nazista e logo os Estados Unidos, 
futuro parceiro econômico para empreendimentos de longo alcance (como a construção da Companhia Siderúrgica Nacional - CSN) e aliado militar na Segunda Guerra Mundial.

Concentrado no registro ficcional da perseguição política vivenciada pelos militantes do Partido Comunista do Brasil, então uma agremiação ilegal e, portanto, de atuação clandestina, Os subterrâneos da liberdade constrói uma trama de fundo didático e maniqueísta (cf. DUARTE, 1995, p. 277) na qual os protagonistas, heróis francamente positivos, estão bem delineados, assim como os seus adversários, verdadeiros e incontestes criminosos ocupando cargos tanto na máquina do Estado quanto em setores chave da economia e da cultura. A perspectiva criativa aqui é a do realismo socialista, doutrina artística e ideológica encampada nessa época (a década de 40 e os primeiros anos da década seguinte) pelo autor. Em linhas gerais, tratava-se de elaborar uma obra socialmente comprometida, baseada nos princípios da propaganda e da agitação política comunista, tal como se havia convencionado, no plano internacional, desde a década de 30. A relativização da importância ficcional do indivíduo (considerado centro da visão de mundo burguesa), a valorização do Partido e das demais organizações de base dos trabalhadores, bem como a exposição dialética - centrada no conflito de classes e na tensão inconciliável entre os valores morais e éticos dos diferentes extratos da sociedade - essas são algumas das características da doutrina estética apropriada por Amado, resultando a composição naquilo que o historiador Daniel Aarão Reis chamou com acerto, no posfácio ao livro, "expressão literária de uma cultura política" (REIS, 2011, p. 352).

Apesar dessa circunstância, que em muito prejudica, ainda hoje, a leitura do texto, é possível observar no corpo do romance a presença de elementos - personagens, cenas, acontecimentos históricos - poucas vezes presentes na prosa de ficção brasileira, alguns até 
então praticamente inéditos. Ainda que todas as ressalvas estéticas e ideológicas possam ser feitas à trilogia de Jorge Amado, permanece, queremos acreditar, a força de certas passagens e o seu significado simbólico de retrato em negativo do país, representação pouco frequente da violência inaudita com que o Estado tratou, e ainda trata, os seus adversários internos e aqueles considerados indesejáveis, cidadãos despojados de qualquer direito. Nesse sentido, observemos o seguinte quadro, disposto pelo autor no terceiro volume da série, A luz no túnel: trata-se de uma situação-limite, a tortura infligida a uma criança de colo, diante de seus pais, para forçá-los a falar, para fazê-los revelar o segredo partidário de que são portadores:

\footnotetext{
- A culpa é de vocês. É melhor falar agora do que depois que a gente começar. Apontou o aparelho de rádio a um tira: ajeitado a criança de costas, ela tentava engatinhar outra vez. Ninguém ouviu seu desesperado grito, foi o de Josefa que todos entenderam, um grito áspero e estranho como se fosse de outra aquela voz, de uma pessoa recém-chegada na sala. [...] (AMADO, 2011, p. 69; grifo nosso)
}

A racionalidade política do que se vê nessa cena não poderia ser mais eloquente, assim como a sua bestialidade, o absurdo que a constitui. A violação do corpo de um bebê, seviciado diante dos pais, é tornada inteligível pelos que a praticaram a partir da culpabilização das vítimas, cujos atos justificariam, pelo seu silêncio no interrogatório e pela ameaça que representam à integridade (desejada) da comunidade nacional, a violência ilegal que, no entanto, se pratica em nome da lei e em defesa de sua manutenção como instituição social. A lógica imanente ao estado de exceção está, nesse caso, em pleno funcionamento: 
tendo como base o perigo revolucionário, cuja atuação se daria justamente na subversão da lei e dos pactos sociais que a sustentam, suspende-se toda e qualquer lei, abriga-se no interior do Estado um conjunto de práticas extrajurídicas que, pela sua natureza, subverte a ordem e o Estado de Direito que originalmente se queria resguardado. A tortura de crianças e incapazes, praticada no Brasil tanto no período do Estado Novo como no momento autoritário posterior (conforme atesta e documenta fartamente o recém-lançado Infância roubada, editado pela Comissão da Verdade do Estado de São Paulo - Rubens Paiva), revela o limite extremo, ou talvez a falta mesma de limites, do poder estatal que se abateu sobre os indivíduos, cujos corpos passaram a ser o palco de uma disputa feroz em torno do controle total e da unidade indivisa de uma nação que, àquela altura, era convidada a marchar para o Oeste, para a expansão das fronteiras econômicas e a consolidação da hegemonia interna por parte do governo.

Para além da exposição que faz da dor e do sofrimento daqueles personagens, figurantes de um drama histórico complexo, a cena que destacamos de Os subterrâneos da liberdade pode ser lida também como índice da negatividade, da disposição para a crítica (e não para a conciliação) da literatura de Jorge Amado, ou pelo menos de parte dela. Majoritariamente lida em função do congraçamento e da mestiçagem, sinais da inflexão conciliatória (de raças, de classes, de conflitos outrora explosivos) que os seus romances passaram a assumir depois de Dona Flor e seus dois maridos (1966), a representação do Brasil e da história que se pode ler, de modo cifrado, na tessitura da trilogia (fixada de maneira exemplar na cena destacada), é eminentemente derrisória e revela a violência constitutiva do país, base das relações sociais profundamente desiguais que se estabeleceram ao longo dos séculos, e foram mantidas por um Estado, nos últimos 100 anos, de feição 
autoritária e conservadora, que recorreu a todo tipo de método restritivo para lidar - em diferentes contextos históricos, como indica a (re)leitura que propomos do legado de Jorge Amado - com a diferença e a contestação: da censura à ilegalidade dos partidos de oposição; a criminalização de movimentos sociais, o engessamento da legislação, o fechamento do espaço público de participação; enfim, a censura, prisão, tortura, extermínio e desaparecimento forçado de dissidentes.

No panorama da literatura brasileira contemporânea, um romance atualiza, como talvez nenhum outro em sua época, a questão persistente do estado de exceção no Brasil. $K$. Relato de uma busca, do jornalista Bernardo Kucinski, elabora, numa narrativa híbrida que situa entre o testemunho e a ficção, o motivo da procura, da investigação que se sabe, desde o início, fadada ao fracasso mas que ainda assim prossegue remexendo memórias, reconstituindo fatos perdidos, imaginando o que a História não registrou (porque apagado), procurando, enfim, pistas que levem ao esclarecimento do mistério: onde estão aqueles que, durante a última ditadura civil-militar (1964-1985), foram presos pelo Estado e nunca mais voltaram para casa, sumindo em pleno ar? Numa importante avaliação do romance e do contexto em que ele surge na cultura brasileira (a publicação, em 2011, é quase coincidente com a instalação da Comissão Nacional da Verdade - CNV), o pesquisador italiano Roberto Vecchi vai dizer que o texto de Kucinski "inaugura uma possibilidade efetiva de escrever a desaparição política" (VECCHI, 2014, p. 142), de algum modo afirmando a lacuna dupla que cercava o tema no Brasil: das vítimas não restavam traços físicos, documentos, nem tampouco 
(é o que implicitamente está dito) havia sobre elas, seu desaparecimento, uma representação literária efetiva, uma política da escrita a altura das especificidades do tema.

Decisivo para a conformação do projeto, o ponto de vista narrativo é duplo, móvel em $K$. Há como que uma alternância de foco: ora o narrador é uma espécie de sobrevivente (aquele que, emergindo depois do naufrágio, resta para contar, para tentar ordenar e compreender os acontecimentos) que conta de maneira direta e reflexiva a busca empreendida por K., um velho erudito judeu, especializado em literatura iídiche, pela sua filha, Ana Rosa Kucinski, desaparecida política; ora o foco narrativo se distribui entre os muitos envolvidos nessa trama, quase todos personagens históricos, que vão falar, cada a um a sua maneira e a partir de seu ponto de vista singular, sobre os acontecimentos relacionados ao extermínio de opositores e à política oficial de apagamento de rastros, da qual a ocultação dos cadáveres é, paradoxalmente, o elemento mais visível e aparente. Vão aparecer nesse esforço ficcional que procura dar voz aos sujeitos da História tanto as vítimas do desaparecimento (a própria Ana Rosa Kucinski, por exemplo, de resto um fantasma do qual pouco se consegue saber) quanto os torturadores e assassinos (dentre os quais destaca-se a figura do sicário Sérgio Paranhos Fleury, delegado de polícia e figura máxima da barbárie repressiva no Brasil). O trecho que escolhemos sublinhar, como se verá, revela, de modo digressivo, os primeiros passos da epopeia negativa de K., ainda atônito pela falta de notícias e perspectivas. São os trechos finais do segundo capítulo, "Sorvedouro de pessoas":

Um rapaz encontrou-se com a esposa no Conjunto Nacional para almoçarem juntos e os dois nunca mais foram vistos. À medida que falava, a mãe do rapaz mostrava aos vizinhos de assento as fotos do filho, da nora e do netinho. Um senhor levantou-se, disse que viera de Goiânia especialmente para a reunião. Seus dois filhos, um de vinte e o outro de apenas dezesseis, foram desaparecidos. Esse senhor gaguejava, parecia em estado catatônico. Foi o primeiro a usar a expressão "foram desaparecidos". Também trazia fotos dos filhos. Depois dele, K. tomou coragem e contou a sua história. 
Já havia caído a noite e os relatos prosseguiam. Variavam cenários, detalhes, circunstâncias, mas todos os vinte e dois casos computados naquela reunião tinham uma característica comum assombrosa: as pessoas desapareciam sem deixar vestígios. Era como se volatilizassem. O mesmo com os jovens do Araguaia, embora estes já se soubesse estarem mortos. A freira anotava caso por caso. Também recolhia as fotos trazidas pelos familiares.

K. tudo ouvia, espantado. Até os nazistas que reduziam suas vítimas a cinzas registravam os mortos. Cada um tinha um número, tatuado no braço. A cada morte, davam baixa num livro. É verdade que nos primeiros dias da invasão houve chacinas e depois também. Enfileiravam todos os judeus de uma aldeia ao lado de uma vala, fuzilavam, jogavam cal em cima, depois terra e pronto. Mas os goim de cada lugar sabiam que os seus judeus estavam enterrados naquele buraco, sabiam quantos eram e quem era cada um. Não havia a agonia da incerteza; eras execuções em massa, não era um sumidouro de pessoas. (KUCINSKI, 2014, p. 22-23; grifo nosso)

Duas ou três questões, dentre as muitas que emergem de uma passagem rica de sugestões como essa, merecem desdobramento. A primeira delas diz respeito à duração do crime, da violência implicada na estratégia do desaparecimento forçado, aqui transformado em matéria romanesca. Ao contrário de várias outras práticas, esta é uma violação que virtualmente não tem fim. A ocultação do cadáver estende indefinidamente a duração da violência, praticada sobre vítima mesmo depois da sua morte. O bloqueio ao luto das famílias e à elaboração social (em sentido freudiano) da perda, imposto pela ausência do corpo, é também uma consequência grave do problema, que acaba funcionando como uma espécie de elo entre o passado e o presente, na medida que a continuidade do impasse reatualiza, permanentemente, o crime, como se ele não cessasse nunca de ocorrer e habitasse, por isso, um presente perpétuo.

Em segundo lugar, o tema do apagamento dos rastros nos parece demasiadamente eloquente e significativo. Em parte repetindo o gesto nazista - que inaugurou, na história moderna, a prática do apagamento da memória -, em parte avançando em relação a ele, aperfeiçoando o seu maquinismo infernal, a política de desaparecimentos forçados no Brasil e na América Latina procurou cancelar, definitivamente, a existência de seus opositores, 
destruindo os seus corpos e apagando, no mesmo gesto, qualquer traço da violência e do próprio sujeito vitimado. Como o texto de Kucinski vai ressaltar, "as pessoas desapareciam sem deixar vestígio", o que nos coloca diante do fato de que a ditadura militar brasileira entrava também, desde o momento do crime, numa disputa pela memória e pela narrativa da repressão política no país. Num gesto que denota cálculo e autoconsciência, os militares vislumbraram o seu eventual afastamento do poder e a luta que a partir daí se daria pela apuração e punição das violações cometidas; antecipando-se ao fato, e redobrando a pena aplicada sobre as vítimas já exterminadas, decide eliminar também os seus restos, criando a tese - tão habilmente incorporada à trama de $K$. - de que não havia vítimas, não havia corpos, não havia mortos: estavam todos vivos, exilados uns, escondidos outros no país, mas todos, sem exceção, não teriam passado nem sequer pela prisão. Existiam, ilesos e sem processo, em algum lugar. A exceção aqui, como o próprio romance alerta, são os combatentes da Guerrilha do Araguaia, admitidos pelo Estado como mortos mas verdadeiramente desaparecidos, dado que os seus corpos jamais foram apresentados e devolvidos às famílias.

Por fim, destacamos que, conforme aponta a leitura de $K$, a questão do desaparecimento forçado indica entre nós mais do que a persistência de um problema político, ou de um traço cultural negativo mas, ao fim, apenas um vício histórico qualquer. Ele expõe a manutenção institucional, mesmo burocrática e militar, nos dias de hoje, das mesmas estruturas de poder e grupos de força que controlaram o Estado durante a ditadura, e que já, pelo menos oficialmente, seria possível considerar derrotados. A insistência no fechamento dos arquivos, a recusa por parte dos comandantes militares em revelar a localização de (pelo menos) parte dos corpos dos desaparecidos, e a negação, profundamente grave, em interromper o funcionamento da máquina repressiva que ainda atua no controle das 
informações e na disposição dos quadros remanescentes do aparato militar, diz a todos, de maneira muito clara e direta, que ainda vivemos sob o mesmo controle, sob as mesmas configurações de poder e micro-poder, apenas adaptadas às novas condições de representação política. Enquanto a "agonia da incerteza" dos desaparecimentos pairar impune sobre as cabeças de todos, os nossos mortos (como Amarildo de Souza, como tantos outros) continuarão sumindo, a exceção permanecerá imposta como regra, a formação de campos de concentração improvisados e a tortura de crianças restará como possibilidade sempre aberta e latente na história brasileira.

\section{Referências}

AGAMBEN, G. Estado de exceção. Trad. Iraci D. Poleti. São Paulo: Boitempo, 2004.

AGAMBEN, G. Homo sacer. O poder soberano e a vida nua I. Trad. Henrique Burigo. Belo Horizonte: Ed. UFMG, 2010.

AMADO, J. Agonia da noite (Os subterrâneos da liberdade I). São Paulo: Companhia das Letras, 2011.

AMADO, J. A luz no túnel (Os subterrâneos da liberdade III). São Paulo: Companhia das Letras, 2011.

AMADO, J. Os ásperos tempos (Os subterrâneos da liberdade II). São Paulo: Companhia das Letras, 2011.

BENJAMIN, W. Teses sobre o conceito da História. In: Magia e técnica, arte e politica. São Paulo: Brasiliense, 2004; p. 222-232.

CARVALHO, J. M. Os bestializados. O Rio de Janeiro e a República que não foi. São Paulo: Companhia das Letras, 1998.

DERRIDA, J. Força de lei. Trad. Leyla Perrone-Moisés. São Paulo: Martins Fontes, 2007.

DUARTE, E. A. Jorge Amado: romance em tempo de utopia. Natal: UFRN Ed. Universitária, 1995.

HARDMAN, F. F. Tróia de Taipa. Canudos e os irracionais. In: Morte e progresso. Cultura brasileira como apagamento de rastros. São Paulo: Ed. UNESP, 1998; p. 125-136.

KUCINSKI, B. K. Relato de uma busca. São Paulo: CosacNaify, 2014.

MIRANDA, W. M. Corpos escritos. São Paulo: Edusp; Belo Horizonte: Ed. UFMG, 1992.

PENNA, J. C. Escritos da sobrevivência. Rio de Janeiro: 7Letras, 2013.

RAMOS, G. Memórias do cárcere. São Paulo: Record, 2008. 
REIS, D. A. Posfácio. In: A luz no túnel. São Paulo: Companhia das Letras, 2011; p. 352-369. VECCHI, R. O passado subtraído da desaparição forçada: Araguaia como palimpsesto. In: Estudos de Literatura Brasileira Contemporânea, n. 43. Brasília: UNB, 2014; p. 133-146. 